\title{
Ophthalmological Society of New Zealand (B.M.A.) \\ VIII ANNUAL CONFERENCE, 1953
}

The Eighth Annual Meeting of the Ophthalmological Society of New Zealand was held in Dunedin on November 4-6, 1953, under the presidency of Mr. W. E. Carswell, F.R.C.S.

It was a pleasure to welcome two distinguished overseas guests, Prof. H. J. Weve, M.D., of the University of Utrecht, Holland, and Mr. A. Seymour Philps, F.R.C.S., of St. Bartholomew's Hospital, London, whose papers added considerably to the interest and value of the meetings. Twenty-four members of the New Zealand Society were present representing just over half of the total membership.

Papers were read by Professor Weve on the "Diathermic treatment of different forms of retinal detachment", and the "Origin and relationship of disinsertions, retinal cysts, folds, and retrolental fibroplasia". Mr. Philps spoke on "Ptosis" and "Anæsthesia". At a combined session with the Department of Neurology, Sir Charles Symonds, Sims Commonwealth Travelling Professor, gave a most interesting talk on " Primary carotid artery thrombosis". Professor J. H. Smirk and Dr. A. E. Doyle of the Department of Medicine contributed a paper on "Retinal changes in hypertension", and Mr. Anthony James spike on "A neuro-surgical approach to failing vision".

Papers were given by members of the Society on a variety of topics: " Retrolental fibroplasia in the Auckland district ", " One hundred extractions with an erisophake ", " Modified McLean suture", "Lens-induced uveitis and glaucoma ", " Two historical ophthalmic cases ", "Mandibulo-facial dystrophy", and "Convergence deficiency".

One evening was devoted to the showing of an extremely good series of films for which the Society was greatly indebted to the overseas visitors. The majority of the papers will be published as an Ophthalmic Supplement to the New Zealand Medical Journal.

At the Annual Dinner it was announced by the President that Prof. Weve and Mr. Philps had both been elected Honorary Members of the Society. Dr. J. S. Munro of Palmerston North was elected President for the ensuing year. It is expected that the next (ninth) Annual Meeting will be held in Palmerston North in November, 1954.

Treacher Collins Prize, 1954

Dr. Robert Leishman of Glasgow has been awarded the Treacher Collins Prize for 1954 by the Ophthalmological Society of the United Kingdom for his essay on "The Eye in General Vascular Disease: Hypertension and Arteriosclerosis".

\section{Percival J. Hay Memorial Prize, 1954}

At the Annual Meeting of the North of England Ophthalmological Society at the Royal Infirmary, Sheffield, on May 29, 1954, the first Percival J. Hay Memorial Prize, value $£ 60$, was awarded to Mr. A. Stanworth, M.B., Ch.B., D.O.M.S., for his paper on "Science and Ophthalmology".

Dr. C. S. SwaN has been appointed Honorary Assistant Ophthalmologist at the Royal Adelaide Hospital, South Australia.

The Gonin Oration at the University of Lausanne was given by Sir Stewart DukeElder on May 19, 1954.

\section{OBITUARY \\ LesLie Gemmill Scoular}

The Editorial Committee regret to announce the death of Dr. L. G. Scoular, M.D., D.O.M.S., which occurred on May 6, 1954. 